RUNNING HEAD: SERVICE TRANSFORMATION IN CAMHS

\title{
A qualitative exploration of the role of leadership in service transformation in child and adolescent mental health services
}

Julian Edbrooke-Childs ${ }^{1}$, Ana Calderon ${ }^{1}$, Matthew McDonnell ${ }^{1}$, Hanna Hirvonen ${ }^{1}$, Jessica Deighton $^{1}, \&$ Miranda Wolpert ${ }^{1}$

\section{Affiliations}

${ }^{1}$ Evidence Based Practice Unit, UCL and the Anna Freud Centre, 12 Maresfield Gardens, London, NW3 5SU

Correspondence regarding this research should be sent to Dr Miranda Wolpert, Director of the Evidence Based Practice Unit, UCL and the Anna Freud Centre, 12 Maresfield Gardens, London, NW3 5SU; +44 (0)20 7443 2225; ebpu@annafreud.org; 


\begin{abstract}
Background: Recent policy in England has called on services for children and young people's mental health and wellbeing to develop and deliver local transformation plans to increase the provision of evidence-based, outcomes-informed, and service user-informed treatments. The role of local leadership in service transformation is poorly understood, despite evidence suggesting it is key to enacting change. Purpose: To understand the role of local leaders and frontline practitioners in service transformation in child and adolescent mental health services. Methodology: Framework approach and thematic analysis of semi-structured interviews with $n=20$ leaders and $n=29$ frontline practitioners in child and adolescent mental health services taking part in a service transformation programme. Results: Leaders' role in service transformation in CAMHS was to: a) foster impetus for transformation by demonstrating passion and commitment for change, b) support practitioners in developing microsystem improvements, and c) bridging the organization's goals with available resources. Conclusions: When developing transformation plans for child and adolescent mental health services, local leaders should be transparent about reasoning and processes, enable practitioners to tailor implementation to need, and provide ongoing support. Practitioner engagement needs careful planning given its crucial role in enabling collaboration that will facilitate change.
\end{abstract}

Keywords: leadership, child and adolescent mental health services, CAMHS, qualitative, service transformation 


\section{Key Practitioner Message}

- CAMH services in England are developing and implementing local sustainable transformation plans to improve service provision for children and young people.

- Past research suggests that local leadership is key to all aspects of service delivery, including transformation.

- Leaders and frontline practitioners described leaders' role in service transformation in CAMHS as fostering impetus for transformation by demonstrating passion and commitment for change, supporting practitioners in developing microsystem improvements, and bridging the organization's goals with available resources.

- Leaders should be transparent about reasoning and processes behind service transformation and enable practitioners to tailor implementation to need.

- Frontline practitioners need ongoing support to engage with service transformation. 


\section{A qualitative exploration of the role of leadership in service transformation in child and adolescent mental health services}

Recent policy in England has called on services for children and young people's mental health and wellbeing to develop and deliver local transformation plans to increase the provision of evidence-based, outcomes-informed, and service user-informed treatments (NHS England, 2015). We know that service transformation is a complex intervention, involving multiple interacting systems (see for example Greenhalgh, Robert, Macfarlane, Bate, \& Kyriakidou, 2004) and that frequent, rapid service transformation is characteristic of the National Health Service (NHS) and reported as a stressor by staff (Majomi, Brown, \& Crawford, 2003). Evidence suggests that local leadership is key to all aspects of service delivery, including service transformation (Department of Health, 2013; West \& Dawson, 2012; Fixsen et al., 2005).

Despite there being a rich evidence base on service transformation in healthcare examining the role of leadership (Greenhalgh et al., 2004; Best et al., 2012), and there being a clear vision of what characteristics an NHS leader should have (e.g., Berwick, 2013), the role of local leadership in service transformation in child and adolescent mental health services (CAMHS) in England is poorly understood. Research is needed on the role of leadership specifically in CAMHS because effective leadership is dependent on context-specific competencies (West, et al., 2015). In addition, the relationship between leaders and frontline practitioners in CAMHS is different to other healthcare settings. In CAMHS, practitioners and teams work autonomously, with frontline clinical practice far removed from management staff as the impetus is on modality-specific clinical supervision, which may not be performed by line managers or even by staff from the same organisation. This article examines the role of local leadership in service transformation in CAMHS through a qualitative exploration of the experiences of leaders and frontline practitioners. 
Leadership in the context of the NHS can be understood as "mobilising the attention, resources and practices of others towards particular goals, values or outcomes... Leaders need first-hand knowledge of the reality of the system at the front line, and they need to learn directly from and remain connected with those for whom they are responsible. Culture change and continual improvement come from what leaders do, through their commitment, encouragement, compassion and modelling of appropriate behaviours." (Berwick, 2013, p. $15)$.

According to the organizational model of transformational change in health care systems (Lukas et al., 2007), leaders have two main roles in service transformation. First, leaders should be committed to the impetus of transformation by demonstrating authentic passion and support for change. Second, leaders should steer transformation by: a) engaging practitioners in microsystem improvements, b) aligning the organization's goals with available resources, and c) bridging boundaries across staff and different units within the organization.

Generally, supportive leadership from line managers has been shown to be associated with lower levels of staff turnover, mental distress, and patient mortality, and higher levels of team innovation, patient satisfaction, and quality of life (Boener et al., 2008; Bronkhorst, Tummers, Steijn, \& Vijverberg, 2015; Corrigan, Lickey, Campion, \& Rashid, 2000; Dawson, West, Admasachew, \& Topakas, 2011; West et al., 2003). Ineffective leadership has been cited as key to failures in patient care (Keogh, 2013). A study examining adoption and nonadoption of service transformation in healthcare found that leaders' engagement of practitioners and "enticing" them to try new practices was key to successful transformation (Reay et al., 2013). In child mental health services in North America, transformational leadership has been shown to be associated with more positive attitudes toward adoption of evidence-based practice and less perceived discrepancy between evidence-based practice and 
current practice (Aarons, 2006). What little research there is on the role of leadership in CAMHS in England has focussed on the need for leadership support in staff training (Edwards et al., 2008).

The present study focusses on the role of leaders and frontline practitioners as collective approaches to leadership (Cullen-Lester \& Yammarino, 2016) advocate "reversing the lens" to examine the role of frontline practitioners or "the characteristics, behaviors and processes of individuals acting in relation to leaders" (Uhl-Bien, Riggio, Lowe, \& Carsten, 2014, p. 96). Thus, leaders and practitioners interact to co-create leadership during service transformation.

The aim of the present research was to address the gap in the literature on the role of local leadership in service transformation in CAMHS in England to inform recommendations about supporting services to deliver local transformation plans set out in recent policy (NHS England, 2015). In particular, our primary research question was: What is the role of local leadership in transforming CAMHS from both leaders' and practitioners' perspectives? To address this question, interviews were conducted and analysed with leaders and frontline practitioners in CAMHS involved in a service transformation programme.

\section{Method}

\section{Participants and procedure}

As part of a national study (Edbrooke-Childs et al., 2015) examining a service transformation (Children and Young People's Improving Access to Psychological Therapies) (CYP IAPT) semi-structured interviews were conducted with $N=92$ staff from 12 purposively sampled services participating in the service transformation. Staff were recruited to take part in an interview either during a team meeting or via email. Interviews were conducted one-toone, either in person or by telephone. Most interviews $(n=86)$ were transcribed verbatim and then analysed, with a minority concurrently transcribed and analysed with notes from 
interviews written up from audio records. From the data corpus, a sample of $n=20$ leader (3 commissioners, 17 managers) and $n=29$ practitioner transcripts were selected and analysed for the present research, including all of the available leader interviews (i.e., commissioners and managers) and a random sample of practitioner interviews, which comprised a greater proportion of total interviews; all practitioner transcripts were not analysed as saturation of themes was achieved. As the aim of the present research was to examine the role of local leadership in transforming CAMHS from both leaders' and practitioners' perspectives, our primary interest was comparing the experiences of leaders and practitioners and not to analyse similarities and differences between the 12 sites in particular. A favourable ethical approval was received from University College London Research Ethics committee (project ID: 6087/001) and the project was registered with local Trusts; all participants gave written informed consent.

\section{Materials and analytic strategy}

The topic guide for the semi-structured interviews included questions about participants' experience of different components of the service transformation programme. Interviews were conducted by Research Assistants who were not part of the service. For the present study, the data set was first partitioned to examine the role of leaders, the role of practitioners, and barriers and facilitators to service transformation using framework analysis (Ritchie \& Spencer, 1993) in NVivo (QSR International Pty Ltd, 2015). Framework analysis can be used to organise according to the five stages outlined below:

1. Familiarisation: embedding and immersion within the whole interview using audio recordings, transcripts, and field notes

2. Identifying a thematic framework: based on emergent themes and a priori expectations

3. Indexing: all items in transcripts are coded with multiple codes permitted

4. Charting: summarising and synthesising all the data for each theme 
5. Mapping and interpretation: to explain and understand findings by exploring consistent, contrasting, and unique occurrences.

Once the data were partitioned, a thematic analysis was conducted, according to the six stages below (Braun \& Clark, 2006):

1. Familiarisation (as above)

2. Generation of codes: one researcher (MM) developed the initial coding framework, and coding was reviewed and discussed with a second researcher (AC)

3. Searching for themes: based on initial codes and a priori expectations, codes were synthesised into broader themes

4. Reviewing themes: transcripts were re-reviewed in light of the final thematic coding framework. A third researcher $(\mathrm{HH})$ coded a random selection of approximately $5 \%$ of transcripts to ensure consistency of coding; mean Kappa and percentage of agreement between raters was calculated (0.81 and 96.79, respectively) indicating high levels of agreement (Terwee et al., 2007). The three coders met regularly for coding meetings to review transcripts and codes and to align any discrepancies.

5. Defining and naming themes: names of themes were reviewed to ensure the core elements of the theme were distilled. Our theoretical model of service transformation (Lukas et al., 2007) was revisited to align names of themes with our theoretical framework.

6. Producing a report: primary and secondary themes and illustrative quotes were initially summarised in a table ahead of drafting of the results, where primary themes are indicated in bold and secondary ones in italics.

\section{Results}

Overall, the role of leadership in service transformation in CAMHS was described as bridging the policy driving the service transformation and how it was actually implemented in daily practice. 


\section{Impetus for transformation}

A central role of the leadership-bridge was fostering the impetus for transformation.

On the one hand, leaders described the service transformation as a positive for improving the quality of patient care whilst facing resistance and concerns from practitioners. On the other hand, practitioners were more questioning of the service transformation and described feeling that it was imposed on them by policy makers. The example of service transformation in the present research was a large-scale initiative implemented by national policy. As such, the role of leaders and practitioners in service transformation was particularly important in fostering local impetus for transformation of a so-called "top-down" initiative. "I think there's a bit of a feeling of [the service transformation] kind of being done to the team rather than the team being part of it. For those who haven't been involved in training, it feels quite top-down." (Site 12, Therapist 2).

Overcoming resistance to change, and promoting acceptance and engagement, were described as being crucial for implementing and sustaining changes to practice, and also for spreading transformation by creating practitioner champions of change. Transparency about the reasons for and requirements of service transformation were crucial to promote engagement; however, some practitioners reported being unsure as to the rationale behind service changes. "I think politically, there was a bit of a feeling of you know, that we were all being... square pegs forced into round holes... a very prescriptive way of delivering a service and this was the new game in town and you all just had to get on board with it. And I think that probably, that was probably just a lot about expectation before it actually arrived...I think it was just about our resistance to change, possibly, or needing to be a bit more convinced of the reasons why we would change and that it wasn't just facilitating a political agenda of cuts, for instance." (Site 2, Therapist 1). "Those that haven't had training... I think 
the people who haven't been involved in it can feel very, trying to think of the right word, disempowered, I think they can be made to feel they are not as good.” (Site 6, Team lead 1).

Resistance was described as stemming from a fear of being appraised and of being devalued, particularly when some staff were attending training as part of the service transformation and others were not: "I think moving people and helping them change when they've been here for a very long time and have been set doing things has been quite tricky... and I think some people have found that, the changes quite hard to kind of get on board with really, so I think introducing it has brought up a number of performance issues and that takes time and energy to kind of work through really, as it would with any change." (Site 11, Team lead 2).

Leaders'demonstration of passion for and commitment to the service transformation was especially important to foster impetus for transformation and overcome resistance: "I guess the key thing that helps is actually having that sense of leadership, and you know, that kind of real sense that this is something we want to do as a service, so you know, having that leadership... which I think helps in terms of then being able to look at how that could be implemented across the whole" (Site 4, Commissioner 1). Some practitioners described leaders as having a lack of knowledge, understanding, or engagement with the service transformation, which undermined the ability of leaders to foster local impetus for transformation. "I don't think our manager has ever...How can they implement [the service transformation] in a service if they're not attending the [service transformation] training and having discussions around it? That's why it does feel a bit like a hierarchical... it does feel a bit like a tickbox exercise." (Site 10, Therapist 2).

Emphasising the service transformation as improving the quality of patient care appeared to help foster local impetus for change: "I don't think there is anyone in the management team who has any objection to [the service transformation] and the worth of it 
or how it will make services more effective, efficient and safe for people in the future and more productive" (Site 7, Team lead 2).

Mirroring the role of leaders, frontline practitioners also described having a role as practitioner champions for service transformation. "I suppose it's that role, you're not just going off and doing a course, you know, part of the role...is actually absorbing some of that culture and bringing it back into the service" (Site 11, Therapist 2). "I think a positive approach from the trainees that have come back, that has been very helpful." (Site 7, Team lead 2). "I think the fact that we have had quite a lot of people trained helps because it creates a body of people within the service who help move it forward, I think it would have been much harder if there had only been one or two people, but there has been a big chunk of practitioners, there's been some supervisors and leads, so it is across the service and that breadth I think helps, and the priority given to it by management, so there has been time for some training days and things like that, that really helps." (Site 4, Therapist 2).

If practitioner champions were initially resistant to change, this appeared to resonate with colleagues' experiences: "The people who have gone off to do the [service transformation] training were very well established, very experienced team members who were respected and those I believe, not resistance but inquisitive cynicism, there were enquiries about be right, 'I've been qualified for 20 years, what can they teach me?' They went off to do the training and it was superb and they loved it and came back really believing in the service transformation...really positive, and I think because they were so well respected it got the team thinking 'actually they are doing it so perhaps there is something in it for me"” (Site 6, Team lead 1).

\section{Microsystem improvements}

Engaging practitioners in the service transformation was described as crucial for microsystem improvements and ensuring that top-down implementation was tailored to 
local need and delivered in daily clinical practice; e.g., "We are updating our website with information from participation groups and it is very visual. This has improved young people's understanding and what they need from CAMHS. They are also on interview panels." (Site 3, Therapist 1). For practitioners to implement microsystem improvements and embed the service transformation, ongoing support from leaders was needed. "You need support from managers and leadership, otherwise you're all just going on a course and then it looks good on your CV but actually you can't implement it in practice, which is frustrating." (Site 10, Therapist 2). "I think the team have taken on more responsibility in relation to developing processes, or putting in place processes for supervision, so what's changed is that they are thinking and working towards developing a policy, and are, and now realise the importance of having those supervision sessions recorded and in patient clinical records." (Site 11, Team lead 1). Types of ongoing support related to practitioners feeling heard, leaders engaging with practitioners' concerns and difficulties, and ongoing support to apply training in practice. Some practitioners reported a lack of ongoing support as a barrier to service transformation: "Supervision tends to be a tickbox exercise and there's not enough time, in my opinion, spent on kind of reflecting and thinking about that. It's more task-orientated.” (Site 10, Therapist 2).

Practitioners described training as the greatest facilitator of culture change in terms of equipping them with the necessary skills to change practice and, moreover, to engage with change as practitioners were informed about the process and aims of the service transformation. "The process of training is extremely supportive and structured and that works very well, that makes it worthwhile and people are enthusiastic to go" (Site 3, Therapist 2). Leadership was described as a crucial source of support and, correspondingly, training and support for leaders to provide this role was also emphasised: "I think it has been good to do the leadership, I think I would have underestimated the need for leadership training for managers and so I think the amount of leadership training there has been really 
good," (Site 6, Therapist 4). In addition to support from leaders, participants reported the value of support from colleagues and between services. "we're very fortunate in that we've got a very supportive [service transformation] team at the moment to help us, so if that wasn't there, that might be a barrier," (Site 10, Team lead 1). "having the [service transformation] project leader...he comes along to our meetings, our transformation groups, and he has also helped me out with a few training things as well, so yeah that has also been really helpful. So I think the fact that if we raise something you feel like you are heard.” (Site 11, Therapist 2). Bridging organizational goals of transformation and resources for transformation Leadership was described as bridging organizational goals of transformation and resources for transformation. Three main resourcing or organizational barriers to service transformation were reported.

First, staff time (regarding funding to cover clinicians' time to attend training), the ability to recruit staff to cover clinicians' time to attend training, and administrative support, all of which resulted in increased clinician workload. "...the barriers are just about having to keep the day job when the changes were happening, in terms of austerity cuts impacting on every bit of the service" (Site 6, Therapist 3). "Caseloads, goes without saying, it's got to be caseloads. But also as I say the reduction of supervision that goes along with that.” (Site 7, Therapist 2).

Second, external pressures and uncertainty over future funding as it was a three-year service transformation programme. "External pressures in terms of cuts, across the children and young people's service and the impact that has had on the service, that puts an increasing demand on the service, with a reduction of staff, our opportunities to provide tier 2 and 3 interventions now is reduced, now at higher levels so tier 3 tier 4 provider. [It's] more difficult to provide evidence-based interventions. That is one of the challenges." (Site 3, Team lead 1). "Lack of continuity of funding... just the fact that budgets are not consistent, 
services are always on the edge of vanishing, it's hard to build a future pathway and develop services when strategically you don't know whether you are going to exist. (Site 4, Therapist $1)$ ”.

Third, information technology, as new systems were implemented, which created a number of challenges, including training to use the new system and incompatibility with existing systems, resulting in double entry of paper forms. "I think that there should be no double entry of data, that when the data is entered that it is meaningful and collated centrally, and doesn't become gobbledegook.” (Site 4, Therapist 1).

\section{Transparency}

In addition to transparency, the rationale for the service transformation and what it would entail being described as facilitators to overcome practitioner resistance to change (see the theme resistance, impetus for change), transparency was also described as an outcome of the service transformation and a bridge between people and organizations. "I think it's made it more of an open relationship between the multidisciplinary team, it's less hierarchal now. It's about that transparency about what people are doing and the training, people's knowledge and expertise has improved, that's made us on an even keel or footing." (Site 9, Therapist 1). "much more of a service now that looks outward and isn't afraid of people looking in, 4 years ago we were an inward-looking service who were afraid of people looking in, so I think we have become more transparent, we can stand by the care pathways, care bundles, user engagement, we are able to report on outcomes and we are trying to improve access and reach out, we are proud of what we have achieved and are able to market and sell what we offer." (Site 3, Team lead 1).

\section{Discussion}

The aim of the present research was to address the gap in the literature on the role of local leadership in transforming CAMHS in England to inform recommendations about supporting 
services to deliver local transformation plans set out in recent policy (NHS England, 2015). In particular, our primary research question was: What is the role of local leadership in transforming CAMHS from both leaders' and practitioners' perspectives? To address this question, interviews were analysed with leaders and frontline practitioners in CAMHS involved in a service transformation programme.

Overall, the role of leadership in service transformation in CAMHS was described as bridging the policy driving the service transformation and how it was actually implemented in daily practice. In line with previous research and the organizational model of transformation change in health care (Lukas et al., 2007), leaders' roles in service transformation in CAMHS were to: a) foster impetus for transformation by demonstrating passion and commitment for change, b) support practitioners in developing microsystem improvements, and c) bridge the organization's goals with available resources. Transparency about the need and scope of transformation was described as a key facilitator of fostering impetus for change. It was also described as a positive outcome of transformation as the organization became more transparent to internal staff and external stakeholders.

A central role of leadership was fostering the impetus for transformation. On the one hand, leaders described the service transformation as positive for improving the quality of patient care whilst facing resistance and concerns from practitioners. On the other hand, practitioners were more questioning of the service transformation and described feeling that it was imposed on them by policy makers. Overcoming resistance to change, and promoting acceptance and engagement, were described as being crucial for implementing and sustaining changes to practice, and also for spreading transformation by creating practitioner champions of change. Transparency about the reasons for and requirements of service transformation were crucial to promote engagement; however, some practitioners reported being unsure as to the rationale behind service changes. 
Leadership was described as enabling practitioners to implement micro-level improvement, ensuring that top-down implementation was tailored to local need and delivered in daily clinical practice. It was also described as providing ongoing support in terms of practitioners feeling heard, leaders engaging with practitioners' concerns and difficulties, and ongoing support to apply training in practice. Ongoing support was needed but not always received to help overcome continuing barriers to implementation, which were most commonly around infrastructure in the service transformation under study. Leaders need to be actively informed, interested, and engaged with both macro-level, top-down processes and micro-level, bottom-up ones to be able to provide effective ongoing support to practitioners. Leadership was described as interactive and dynamic whereby leaders and practitioners collectively act and co-create the "leadership process" (Uhl-Bien, et al., 2014). When the leadership process was most effective, frontline practitioners adopted a leadership role becoming champions of service transformation.

Limitations should be considered when interpreting the findings of the present research. As the interviews were not conducted solely for the purpose of the present study, some aspects or questions may not have been asked. However, as a comprehensive, semi-structured interview schedule - which included questions on staff perceptions and experience of service transformation-was used we think that this is unlikely. Similarly, the service transformation under study was a national, top-down change; although this involved partnerships tailoring implementation to local need, future research is needed to examine the role of leaders and practitioners when implementing service transformation originating from the bottom-up. An examination of the views, experiences, barriers, and facilitators reported by staff in implementing each of the principles of the service transformation-which was beyond the scope of the present article-may provide further information about different roles during service transformation. Nevertheless, the findings of the present research are based on a large 
sample of interviews conducted about a contemporary service transformation programme currently being rolled out across England. Moreover, framework analysis was used, which is appropriate given the large number of transcripts analysed and the focus on policy research (Ritchie \& Spencer, 1993).

Notwithstanding the above limitations, the present research fills two important gaps in the literature by examining leadership during service transformation in CAMHS and by examining the role of leaders and practitioners. In the present national service transformation, both leaders and practitioners described the role of local leadership as being a bridge between top-down policy implementation and bottom-up clinical practice. This bridge enabled leaders and practitioners to collectively act and co-create the "leadership process", in terms of overcoming resistance to change and the top-down imposition of change on practitioners, enabling micro-level implementation of change, and providing ongoing support. When designing and delivering local transformation plans in CAMHS, findings of the present research suggest that local leaders should be transparent about the reasons for and processes of transformation, enable practitioners to tailor implementation to contextual need, and provide ongoing support to practitioners. Engagement of practitioners needs careful planning in the design of service transformation given its crucial role in enabling collaboration that will facilitate enduring change.

\section{Acknowledgment}

This is an independent report commissioned and funded by the Policy Research Programme in the Department of Health. The views expressed are not necessarily those of the Department. The Child Policy Research Unit (CPRU) is funded by the Department of Health Policy Research Programme. The authors would like to thank members of CPRU: Terence Stephenson, Catherine Law, Amanda Edwards, Ruth Gilbert, Steve Morris, Helen Roberts, Cathy Street, and Russell Viner.

\section{Study funding}

This is an independent report commissioned and funded by the Policy Research Programme in the Department of Health.

Declaration of interest: None 
Contributorships: All authors contributed to the conception and design, or collection, analysis and interpretation of data; and drafting the article or revising it critically for important intellectual content and final approval of the version to be published.

\section{References}

Aarons, G. A. (2006). Transformational and transactional leadership: Associations with attitudes toward evidence-based practice. Psychiatric Services, 57(8), 1162-1169. doi: 10.1176/appi.ps.57.8.1162

Avolio, B. J., Walumbwa, F. O., \& Weber, T. J. (2009). Leadership: Current Theories, Research, and Future Directions. Annual Review of Psychology, 60(1), 421-449. doi: 10.1146/annurev.psych.60.110707.163621

Berwick, D. (2013). A promise to learn-a commitment to act: Improving the Safety of Patients in England. Department of Health. Retrieved from http://www.gov.uk/government/uploads/system/uploads/attachment_data/file/226703/ Berwick_Report.pdf

Best, A., Greenhalgh, T., Lewis, S., Saul, J. E., Carroll, S., \& Bitz, J. (2012). Large-system transformation in health care: a realist review. The Milbank Quarterly, 90(3), 421456.

Bronkhorst, B., Tummers, L., Steijn, B., \& Vijverberg, D. (2015). Organizational climate and employee mental health outcomes. Health Care Management Review, 40(3), 254-271. doi: $10.1097 / \mathrm{hmr} .0000000000000026$

Bryman, A. (2004). Qualitative research on leadership: A critical but appreciative review. The Leadership Quarterly, 15(6), 729-769. doi: 10.1016/j.leaqua.2004.09.007 
Corrigan, P. W., Lickey, S. E., Campion, J., \& Rashid, F. (2000). Mental health team leadership and consumers' satisfaction and quality of life. Psychiatric Services, 51(6), 781-785. doi: 10.1176/appi.ps.51.6.781

Cullen-Lester, K. L., \& Yammarino, F. J. (2016). Collective and network approaches to leadership: Special issue introduction. The Leadership Quarterly. doi: 10.1016/j.leaqua.2016.02.001

CYP IAPT. (2013). National curriculum for core, cognitive behavioural therapy, parenting training (3-10 year olds), systemic family practice, interpersonal psychotherapy for adolescents, supervision, and transformational service leadership. London: IAPT.

CYP IAPT (Ed.). (2014). CYP IAPT principles in CAMH services: Values and standards: "Delivering with and delivering well". London: CAMHS Press.

CYP IAPT (Ed.). (n.d.). Delivering with and delivering well. London: CAMHS Press

Dawson, J. F., West, M. A., Admasachew, L., \& Topakas, A. (2011). NHS Staff Management and Health Service Quality: Results from the NHS Staff Survey and related data. Report to the Department of Health. Retrieved from www.dh.gov.uk/health/2011/08/nhs-staff-management/

Department of Health. (2011). Talking therapies: A four-year plan of action. London. Department of Health. (2012). IAPT three-year report: The first million patients. London. Department of Health. (2013). Patients First and Foremost: The Initial Government Response to the Report of the Mid Staffordshire NHS Foundation Trust Public Inquiry (Vol. 8576). London: The Stationery Office.

Edbrooke-Childs, J., Calderon, A., Wolpert, M., \& Fonagy, P. (2015). Children and young people's improving access to psychological therapies: Rapid internal audit national report. Evidence-Based Practice Unit, Anna Freud Centre/University College London. Retrieved from https://www.ucl.ac.uk/drupal/evidence-based-practice- 
$\underline{\text { unit/sites/evidence-based-practice- }}$

$\underline{\text { unit/files/pub_and_resources_project_reports_rapid_internal_audit_2015.pdf }}$

Edwards, R., Williams, R., Dogra, N., O'Reilly, M., \& Vostanis, P. (2008). Facilitating and limiting factors of training available to staff of specialist CAMHS. The Journal of Mental Health Training, Education and Practice, 3(3), 22-31.

Fixsen, D. L., Naoom, S. F., Blase, K. A., \& Friedman, R. M. (2005). Implementation research: a synthesis of the literature. Retrieved from http://nirn.fpg.unc.edu/sites/nirn.fpg.unc.edu/files/resources/NIRN-MonographFull01-2005.pdf

Greenhalgh, T., Robert, G., Macfarlane, F., Bate, P., \& Kyriakidou, O. (2004). Diffusion of innovations in service organizations: systematic review and recommendations. Milbank Quarterly, 82(4), 581-629. doi: 10.1111/j.0887-378X.2004.00325.x

Keogh, B. (2013). Review into the quality of care and treatment provided by 14 hospital trusts in England: overview report. Retrieved from http://www.nhs.uk/NHSEngland/bruce-keogh-review/Documents/outcomes/keoghreview-final-report.pdf

Majomi, P., Brown, B., \& Crawford, P. (2003). Sacrificing the personal to the professional: community mental health nurses. Journal of Advanced Nursing, 42, 527-538. doi: 10.1046/j.1365-2648.2003.02652.x

NHS England. (2015). Future in mind: Promoting, protecting and improving our children and young people's mental health and wellbeing. Department of Health: London.

QSR International Pty Ltd. (2015). NVivo qualitative data analysis (Version 11).

Ritchie, J., \& Spencer, L. (1993). Qualitative data analysis for applied policy research. In A. Bryman \& R. Burgess (Eds.), Analysing qualtiative data (pp. 173-194). London: Routledge. 
Terwee, C. B., Bot, S. D. M., de Boer, M. R., van der Windt, D. A. W. M., Knol, D. L., Dekker, J., ... de Vet, H. C. W. (2007). Quality criteria were proposed for measurement properties of health status questionnaires. Journal of Clinical Epidemiology, 60(1), 34-42. doi: 10.1016/j.jclinepi.2006.03.012

Uhl-Bien, M., Riggio, R. E., Lowe, K. B., \& Carsten, M. K. (2014). Followership theory: A review and research agenda. The Leadership Quarterly, 25(1), 83-104. doi: 10.1016/j.leaqua.2013.11.007

West, M. A., Armit, K., Loewenthal, L., Eckert, R., West, T., \& Lee, A. (2015). Leadership and leadership development in health care: The evidence base. London: Faculty of Medical Leadership and Management.

West, M. A., Borrill, C. S., Dawson, J. F., Brodbeck, F., Shapiro, D. A., \& Haward, B. (2003). Leadership clarity and team innovation in health care. The Leadership Quarterly, 14(4-5), 393-410. doi: 10.1016/s1048-9843(03)00044-4

West, M. A., \& Dawson, J. (2012). Employee engagement and NHS performance. London: The King's Fund. 